\title{
Value of Laboratory Experiments for Code Validations
}

\author{
Wolfgang R. Wawersik \\ Geoscience and Environment Center \\ Sandia National Laboratories* \\ Albuquerque, NM 87185-0751
}

\section{Introduction}

Numerical simulations and design analyses have become indispensable tools in all branches of the sciences and engineering. They are important in the geosciences and geotechnical engineering because of the spatial and temporal scales of natural systems and the associated difficulties in breaking down problems into continuum and discrete elements including major structural features such as faults, fracture networks, and bedding planes. These problems are compounded by complexities in the behavior of geologic materials (pressure dependence, volumetric response, strain softening, etc.), difficulties in determining constitutive relations, measuring (directly or indirectly) the material properties of heterogeneous media, evaluating the coupling between mechanical, hydrologic and chemical processes, and establishing initial and boundary conditions. Numerical analyses have become valuable partly because they permit large numbers of calculations to be performed. Therefore, for example, the results of parametric studies can be used to narrow the uncertainty about the response of geologic systems to natural or anthropogenic perturbations. Given both the difficulties and uncertainties involved, however, it has become mandatory to establish means of evaluating which of many possible computed outcomes is closest to reality. This latter process is referred to as design or code validation that entails mathematical as well as physical scrutiny.

There is no doubt that geoscience predictions ultimately must be tested in situ using large-scale experiments, involving several cubic meters of rock, and back analyses of the behavior of engineered systems and geologic analogues. Figure 1 provides an example of an in situ experiment that was conducted during the planning for the geologic disposal of low-level radioactive waste in rock salt. The particular experiment shown was essential for the licensing of the Waste Isolation Pilot Plant (WIPP) near Carlsbad, New Mexico, but it was also very costly and time-consuming. Most important, by itself, the test shown did not yield all of the independent measurements needed to discriminate between several possible causes of early, large discrepancies between code predictions and measurements. Later successful adjustments in modeling the deformation of rock salt at the site involved a series of changes among them (1) a change in flow rule from von-Mises to Tresca-type, (2) a change in the hardening rules of rock salt undergoing loading and unloading, and (3) a reevaluation of the salt mass lithology (Munson et al., 1989; Munson, 1997).

\footnotetext{
* Sandia is a multiprogram laboratory operated by Sandia Corporation, a Lockheed Martin Company, for the United States Department of Energy under Contract DE-AC04-94AL85000.
} 


\section{DISCLAIMER}

This report was prepared as an account of work sponsored by an agency of the United States Government. Neither the United States Government nor any agency thereof, nor any of their employees, make any warranty, express or implied, or assumes any legal liability or responsibility for the accuracy, completeness, or usefulness of any information, apparatus, product, or process disclosed, or represents that its use would not infringe privately owned rights. Reference herein to any specific commercial product, process, or service by trade name, trademark, manufacturer, or otherwise does not necessarily constitute or imply its endorsement, recommendation, or favoring by the United States Government or any agency thereof. The views and opinions of authors expressed herein do not necessarily state or reflect those of the United States Government or any agency thereof. 


\section{DISCLAIMER}

Portions of this document may be illegible in electronic image products. Images are produced from the best available original document. 
It is the thesis of this paper that cost and time could be saved if the combination of material models and numerical codes for geoscience and geotechnical analyses were tested earlier and more systematically in laboratory or bench-scale experiments than is the current practice, not instead but before or at least concurrent with the implementation of what could be a significantly smaller number of in situ studies. Besides being costeffective, it is easier to control laboratory tests than it is to control measurements in the field. Towards this end, three examples of past and ongoing work will be discussed to encourage the thinking about laboratory tests for validating numerical (code) analyses and design procedures.

\section{Model Evaluations in Laboratory Pressurized Thick-Walled Cylinder Tests}

Beginning in 1975, laboratory creep measurements were combined with the development of a large-strain finite element code to predict the stress states and closure rates in rock salt at the WIPP site. In order to evaluate the predictive capabilities of this approach, a nearly 1 mile long, $3.7 \mathrm{~m}$ by $6.1 \mathrm{~m}$ drift was advanced in virgin ground soon after a shaft had been sunk to a depth of $655 \mathrm{~m}$. The drift was heavily instrumented with multipoint extensometers to monitor both the vertical and horizontal convergences with time. After a period of approximately three years, highly reproducible measurements were gathered at separate cross-sections indicating that the formation was remarkably homogeneous. Concern arose when it was discovered that the in situ measurements exceeded the calculated deformations and convergence rates by factors of three to five. Because of multiple sources of possible errors, it was not readily possible to identify and aaccount for the causes of disagreement. Conceivable sources of error were (1) differences between the thermomechanical behavior of salt core in laboratory tests and of salt masses in situ; (2) errors in generalizing one and two-dimensional axisymmetric thermomechanical measurements on salt to three dimensions; (3) effects of mean stress, dilatancy, and small amounts of brine; (4) omission of instantaneous plastic strains from the simulations; (5) incorrect descriptions of transients and history effects; (6) model generalizations from tests with homogeneous stress states without regard to possible effects of stress gradients, and (7) inaccuracies in stratigraphic idealizations.

Concern for time and for the considerable number or error sources suggested a well controlled independent study of the predictive accuracy of the constitutive model and flow rule that had been implemented in the finite element code SANCHO (Stone et al., 1984). To accomplish this, it was important to eliminate any differences between salt behavior in situ and salt response in the laboratory after coring and laboratory sample preparation of this inherently weak rock. Such unknown history effects were avoided by relatively simple tests on thick-wall cylinders of rock salt that had undergone the identical coring and machining procedures as solid rock salt cylinders subjected to a variety of rock properties measurements in triaxial quasi-static and creep (constant stress) compression over the same range of stresses and temperatures. An assembly of the experimental setup is shown in Figure 2. The length, outside diameter of the sample, and central hole were $16.5 \mathrm{~cm}, 12 \mathrm{~cm}$, and $3.8 \mathrm{~cm}$, respectively. 
Using existing triaxial testing machines, instrumentation, and jacketing techniques, sample assemblies of the type shown in Figure 2 were subjected to predetermined combinations of stresses acting in the central hole of the thick-walled sample, around the circumference of the sample, and (in the axial direction) across the sample ends. Because the principal stresses could be controlled independently, it was possible to monitor sample responses along several, well defined true three-dimensional stress paths at either constant or varying mean stresses. Figure 3 shows the combination of boundary conditions of one particular sample. A conventional axisymmetric triaxial creep tests during Stage 1 established the connection between the constitutive properties of the thickwall cylinder sample with data base used for the formulation of several constitutive models (Krieg, 1984; Munson et al., 1989). Subsequent combinations of tractions during Stages 2 to 4 tested the predictive qualities of the constitutive models with special attention to the consequences of generalizing axisymmetric creep measurements either by von Mises or Tresca stress measures. Experimental imperfections were included in the analyses by bounding values of friction coefficients between the salt sample and the steel end caps (Figure 2-5). All of these effects were evaluated by calculating the applicable stress paths in the deviatoric (pi) plane (Figure 4) and by comparing the predicted axial, and radial deformation histories with the measured data. Examples of these comparisons are shown in Figures 5 and 6 . The calculated displacements shown were based on two constitutive models using either the von Mises or the Tresca stress generalizations assuming normality. The ESC model (Krieg, 1984) was used for long-term predictions early during the development of WIPP and treated only steady-state creep and, therefore, could not simulate the transient response of the material. The model could, however, predict local "geometric" transients due to time-dependent redistribution of the stress field. The M-D (Munson-Dawson; Munson, 1997) has become the baseline model for WIPP and is capable of capturing both geometric effects and material transients caused by microstructural material adjustments. Although these experiments were not funded beyond a trial stage, the comparisons of the attendant simulations have shown that the von Mises and Tresca flow criteria produce distinctly different responses. The distinctions change with the magnitude of friction between the end-caps and the sample but do not diminish qualitatively. The most noticeable features are the absence of transients in the computed axial displacements for Tresca during Stage 4 and the rates of change of the internal hole diameter that are 1.5 to 2 times larger in the Tresca than in the von Mises models. Such qualitative as well as quantitative differences demonstrate the importance of laboratory validation experiments that include the comparisons of model predictions with the reality of experimental measurements. The potential value of such tests obviously is enhanced by the fact that the measurements in Figures 5 and 6 during 7.5 months of run time had become available within little over one year after the design of the experiments had been started.

\section{Stacked-Plate Experiment to Compare Code Predictions of Fractured Rock Behavior}

Analyses in support of the performance assessment of the proposed Yucca Mountain site for commercial high-level waste isolation in Nevada brought on concerns about potential differences in calculated rock mass deformations in the vicinity of excavations at high 
temperatures. In particular, the question arose as to how to evaluate numerical predictions using computer codes that either treated fractured rock as (1) a continuum with fracture-dominated "effective" mechanical rock properties (smeared approach; Thomas, 1982) or (2) a system of discrete rock blocks separated by discontinuities with different and distinct constitutive properties (Cundall and Strack, 1979; Itasca, 1991) In both cases, the validity of the computational results again is inextricably linked to the validity of the constitutive models chosen including their mathematical form and the values of the individual constitutive parameters.

Deliberations of experimental possibilities either in the laboratory or in the field suggested that conclusive evaluations of the two modeling approaches would hinge on an ability to accurately identify and characterize natural fractures in the test volume, create well-defined boundary conditions, and include a sizable number of fractures in the test volume. It appeared quite difficult to meet all three of these requirements under any circumstances until Brown (1994) and his colleagues suggested the use of laboratory tests using stacks of polycarbonate plates in lieu of fractured rock. Although polycarbonate and polycarbonate surfaces are not rock and joint surfaces, the approach was justified because the forms of the material models of the polycarbonate as well as the interfaces between the individual polycarbonate layers were or could be made the same as the forms of the constitutive models for matrix rock and rough, uncemented natural fractures that had been implemented in several finite element codes. For example, under the same loading conditions, tuff was characterized as a linear elastic material, albeit with different elastic constants as polycarbonate. In turn, interface properties of polycarbonate plates tested in rotary shear (Brown, 1994) could be fitted to the same equations that had been used to characterize natural fractures in tuff.

Figures 7-9 show how the foregoing experimental approach was implemented and used to compare code calculations based on the finite element program JAC2D (Biffle, 1984) and the discrete element code UDEC (Itasca, 1991). The effect of general, inhomogeneous stress states on fractured rock response around underground openings was physically simulated in uniaxial loading tests on stacks of $0.625-\mathrm{cm}$ thick Lexan plates containing a $3.8-\mathrm{cm}$ diameter circular hole shown schematically in Figure 7 . The use of high-density grids in one quadrant around the hole permitted full-field displacement measurements to be made by means of phase-shifted Moire interferometry with an initial resolution of about one micron (Brown, 1994; Perry et al., 19995). Selected results in Figure 8 again demonstrate the importance of comparing code predictions with well-defined experiments. The results shown and additional data (not shown; Sobolik and Miller, 1996) suggest good far-field agreement between JAC2D and UDEC simulations. However, even the simple parallel, regularly spaced "joints" system normal to the direction of loading yields two slip distributions that are distinctly different from one another in the patterns of slip around the circular hole and in the magnitude of slip at particular locations (Figure 8). It may be important for the design of support systems or transport analysis that the points of maximum slip (Figure 8) according to the discrete UDEC simulations moves to higher interfaces as the applied uniaxial stress is increased (Perry et al., 1995; Sobolik and Miller, 1996). At this point, it remains troublesome that the values of the greatest calculated interface slip for UDEC calculations appear to 
exceed the greatest measured slip data by more than an order of magnitude (Figure 9). Intuitively, it is not obvious that this discrepancy is the result of a linear treatment of joint normal stiffness in UDEC versus a hyperbolic stress-joint-closure model to calculate effective continuum properties in JAC2D. Whatever the cause, a well-controlled laboratory experiment reduces the number of uncertainties and, therefore, offers an opportunity to resolve differences in results for meaningful comparisons of design procedures.

The results presented in Figures 8 and 9 underscore the potential of laboratory tests as integral parts of validating numerical models and geotechnical design procedures even if the experiments chosen prove to be difficult. In this example, successful code comparisons relied on a non-trivial advancement of the Moire method for full-field strain and displacement measurements. Therefore, the total development time of the experiment (Brown, 1994) with major improvements by Perry et al. (1995) was approximately two years. Such time delay may be difficult to accept in general engineering practice but remains attractive in comparison with the cost and normal schedules of field validation tests.

\section{Few-Particle Experiments to Support Discrete Element Representations of Cemented Granular Materials}

Discrete (distinct) element computer codes are now being used to simulate the behavior of loose granular or blocky materials, connect the micromechanical and bulk behaviors of porous media, and understand the grain-scale disaggregation of high porosity rocks during sand production around oil wells. Discrete element calculations are also being considered for modeling the propagation of hydraulic fractures in high porosity rocks and to assess whether rock might disaggregate during the injection of liquid-solid waste mixtures. One of these codes, DMC ( Distinct Motion Code) by Preece (1992), has been very successful in mine blast design. A number of features of this code have recently been integrated into the MIT discrete element code MIMES (Rege, 1996) for the treatment of porous materials with arbitrary particle shapes, intergranular cementation, intra- and inter-particle deformation and failure, porous fluid flow, and discrete particle transport as an end result (O'Connor et al., 1997). Like some other codes (Bruno, 1994; Antonellini and Pollard, 1995), MIMES is capable of mimicking the qualitative features of porous rock behavior ranging from distributed microfracturing to strain localization along shear bands with dilation or compaction. It is not clear, however, when MIMES or similar codes will produce quantitatively accurate results. While it is possible to define the rock texture using standard observational methods, quantitative answers with defined uncertainty require methods for (1) validating the conceptual models used for interparticle interactions and (2) determining the material properties called for by the code.

At this point, interparticle interactions in MIMES are represented by bonds acting through the centroids of all contact surfaces. Specifically, particle interactions across each contact are simulated by a single bond capable of resisting actions parallel as well as perpendicular to the bond direction, i.e., to the direction of the link between the adjacent particle surfaces. If the particles consist of spheres, then each two-particle contact is 
limited to a single surface. Because MIMES admits arbitrary particle shapes (Rege, 1996; O'Connor et al., 1997), adjacent particles may touch each at several surfaces each of which results in loading across one bond. In its current form, MIMES bonds cannot carry moments. Interparticle forces and particle displacements are determined by linear bond constitutive models with prescribed stiffnesses for compression, tension, and shear. The bond stiffnesses go to zero and a constant with interparticle failure, respectively, when the bond compression or tension reach specified bond strengths. Similarly, interparticle shear is governed by pre-assigned values for cohesion and friction coefficient. This conceptual model for interparticle behavior is the simplest generalization of the older DMC code applied to loose granular or blocky solids in blasting. Based on existing analytical and finite element analyses, it appears that this model for blocky solids (and similar models in other discrete element codes) may have to be modified. For example, Dvorkin et al. (1991) found that the stress distribution in cements is strongly influenced by the distribution of the cement and the ratio of the grain and cement (elastic) moduli. Additionally, Dvorkin et al. determined that "noticeable shear stresses may develop under normal compression in a cement layer of changing thickness." Because the particles in MIMES are rigid, further changes in interparticle stresses must be anticipated compared with the results for deformable grains. Finite element analyses of Shar and Wong (1998) also demonstrate some conditions for failure which, in principle, can occur in the cement, along the grain-cement bonding surfaces, or within the grains. It is unlikely that all of these effects plus the possible presence of moments at cemented particle contacts can be captured quantitatively by the existing interparticle links and bond constitutive formulations.

Some of the questions above can be answered effectively by finite element analyses of two- and few-particle contacts where details can be considered including irregular grain shapes and the best available constitutive descriptions of grains and natural cements (for example, Wong and $\mathrm{Wu}, 1996$ ). As a physical step, however, tests are being developed to evaluate and generalize the conceptual model for interparticle interaction in MIMES as shown schematically in Figure 10. Two-particle response will be approximated by the interaction between a single particle and a flat surface with intervening cement . Starting with spherical particles (Figure 11), four types of loading conditions will be applied: pure normal loading (compression and tension), shear, and loading by moments about axes parallel and normal to the plane of contact. The bond area and thickness of the cement will be controlled by a combination of capillary forces, initial cement volume, particle radius, and standoff distance between the particle and the flat surface. System behaviors will be monitored by means of force-displacement measurements. It is anticipated that these experiments will establish a well-defined qualititative and quantitative link between numerical simulations and reality.

\section{Summary and Conclusions}

Numerical codes have become indispensable for designing underground structures and interpretating the behavior of geologic systems. Because of the complexities of geologic systems, however, code calculations often are associated with large quantitative uncertainties. This papers presents three examples to demonstrate the value of laboratory 
(or bench scale) experiments to evaluate the predictive capabilities of such codes with five major conclusions:

- Laboratory or bench-scale experiments are a very cost-effective, controlled means of evaluating and validating numerical codes, not instead of but before or at least concurrent with the implementation of in situ studies.

- The design of good laboratory validation tests must identify what aspects of a code are to be scrutinized in order to optimize the size, geometry, boundary conditions, and duration of the experiments .

- The design of good and sometimes difficult laboratory validation tests must involve numerical analyses and sensitivity studies.

- Good validation experiments will generate independent data sets to identify the combined effect of constitutive models, model generalizations, material parameters, and numerical algorithms.

- Successful validations of numerical codes mandate a close collaboration between experimentalists and analysts drawing from the full gamut of observations, measurements, and mathematical results.

\section{Acknowledgements}

I gratefully acknowledge helpful discussions with my colleagues S.R. Brown, H.S. Morgan, J. Jung, J. Epstein, D.S. Preece, R. O'Connor, and S. Sobolik.

\section{References}

Antonelli, M.A., and Pollard, D.D., 1995, Distinct element modeling of deformation bands in sandstone, J. Struct. Geol., 17,8, 1165-1182.

Biffle, J.H., 1984, JAC-a two-dimensional finite element computer program for the nonlinear quasistatic response of solids with the conjugate gradient method, Report SAND81-0998, Sandia National Laboratories, Albuquerque, NM 87185.

Brown, S.R., 1994, Laboratory measurements of frictional slip on interfaces in a polycarbonate rock mass model, Report SAND93-2365, Sandia National Laboratories, Albuquerque, NM 87185.

Brown, S.R., and Hardy, R.D., Geometric Moire method of strain analysis with displacement discontinuities, Report SAND93-1157, Sandia National Laboratories, Albuquerque, NM 87185.

Bruno, M.S., 1994, Micromechanics of stress-induced permeability anisotropy and damage in sedimentary rock, Mech. Materials, 18, 31-48.

Cundall, P.A., and Strack, O.D.L., 1979, A discrete numerical model for granular assemblies, Geotechnique, 29, 47-65.

Dvorkin, J., G. Mavko, and A. Nur, 1991. The effect of cementation on the elastic properties of granular materials, Mech. Mater., 12, 207-217. 
Ithsca Consulting Group, Inc., 1991, UDEC - Universal Distinct Element Code, Version ICG 1.7, User's Manual.

Itasca Consulting Group, Inc., 1995, PFC2D, Particle flow code in two dimensions, User's Manual, Itasca Consulting Group, Inc. Minneapolis, MN.

Jung, J., and Brown, S.R., 1995, A study of discrete and continuum joint modeling techniques, in Fractured and Jointed Rock Masses, Myer, Cook, Goodman, and Tsang, eds., A.A. Balkema, 671-678.

Morgan, H.S., and Wawersik, W.R. 1991, The use of thick-walled cylinder creep tests for evaluating flow criteria for rock salt, Proc. $7^{\text {th }}$ Int. Congr. Rock Mech., A.A. Balkema, Vol. 1, 303-310.

Munson, D.E., 1997, Constitutive model for creep in rock salt applied to underground room closure, Int. J. Rock Mech. Min. Sci., 34, 2, 233-247.

Munson, D.E., Fossum, A.F., and Senseny, P.E., Advances in resolution of discrepancies between predicted and measured in situ WIPP room closures, Report SAND88-2948, Sandia National Laboratories, Albuquerque, NM 87185.

O'Connor, R.M., Torczynski, J.R., Preece, 1997, D.S., Klosek, J.T., and Williams, J.R., Discrete element modeling of sand production, Int. J. Rock Mech., Min. Sci., 34, 3-4, paper no. 231.

Perry, K.E., Buescher, B.J., Anderson, D., and Epstein J.S., 1995, Frictional sliding in layered rock model: preliminary experiments, Report SAND94-2384, Sandia National Laboratories, Albuquerque, NM 87185.

Preece, D.S, and Knudsen, S.D., 1992, Computer modeling of gas flow loading of rock in a bench blasting environment, Proc. $33^{\text {rd }}$ US Rock Mech. Symp., A.A. Balkema, 295-303.

Rege, N.V., 1996, Computational modeling of granular materials, $\mathrm{PhD}$ Thesis, Dept. Civil Environm. Engr. Massachusetts Institute of Technology, Cambridge, MA.

Shar, K, and Wong, T.-F., 1998, Fracturing at contact surfaces subjected to normal and tangential loads, Int. J. Rock Mech. Min. Sci.,

Sobolik, S.R., and Miller, J.D., 1996, Preliminary validation of rock mass models by comparison to laboratory frictional sliding experiments, Report SAND95-2001, Sandia National Laboratories, Albquerque, NM 87184.

Stone, C.M., Krieg, R.D., and Beisinger, Z.A., 1984, SANCHO - a finite element computer program for the quasistatic, large deformation, inelastic response of twodimensional solids, Report SAND84-2618, Sandia National Laboratories, Albuquerque, NM 87185.

Thomas, R.K., 1982, A continuum description for jointed media, Report SAND81-2615, Sandia National Laboratories, Albquerque, NM 87184.

Wawersik, W.R., and Morgan, H.S., 1987, Evaluating design procedures for structures in rock salt, Proc. $28^{\text {th }}$ US Symp. Rock Mech., A.A. Balkema, 107-115.

Wong, T.-F., and Wu, L.C., 1995, Tensile stress concentration and compressive failure in cemented granular material, Gephys. Res. Ltrs., 22, 13, 1649-1652. 


\section{Figures Captions}

Figure 1 - One of several in situ test facilities in the WIPP (room A2 with dimensions $5.5 \times 5.5 \times 9.3 \mathrm{~m})$.

Figure 2-Sample/end cap assembly of pressurized, thick-wall hollow cylinder test and corresponding structural model (from Wawersik and Morgan, 1987, and Morgan and Wawersik, 1991).

Figure 3 - Stress (pressure) and temperature histories applied to a pressurized thickwalled cylinder shown in Figure2 (from Morgan and Wawersik, 1991).

Figure 4 - Deviatoric stress distributions computed for Test 1 with M-D model (see text), zero friction between sample and end caps (Figure 2), and (a) von Mises flow rule and zero and (b) Tresca flow rule. Note general 3-D stress fields achieved in experiment. True three-dimensional loadings were preceded by conventional axisymmetric triaxial creep measurements (Stage 1) for comparison with existing data base (from Morgan and Wawersik, 1991).

Figure 5 - Comparison of computed and measured axial displacement histories for hollow cylinder Test 1 using two different constitutive models (ESC and M-D, see text), von Mises and Tresca flow rules, and the influence of experimental imperfections evaluated for bounding end-friction coefficients of $\mu=0$ and $\mu=0.18$ (from Morgan and Wawersik, 1991).

Figure 6 - Comparison of computed and measured radial displacement histories in central hole of same hollow cylinder Test 1 shown in Figure 5 using two different constitutive models (ESC and M-D, see text), von Mises and Tresca flow rules, and the influence of experimental imperfections evaluated for bounding end-friction coefficients of $\mu=0$ and $\mu=0.18$ (from Morgan and Wawersik, 1991).

Figure 7 - Schematic and dimensions of layered polycarbonate (rock mass) model for uniaxial loading tests perpendicular to layer direction. Layer/plate slip was measured by means of Moire interferometry using grids bonded to one model quadrant surrounding circular hole (Jung and Brown, 1992).

Figure 8 - Comparison of calculated and measured slip around circular hole in model of Figure 8 subjected to $2.56 \mathrm{MPOa}$ uniaxial stress normal to layering (from Jung and Brown, 1992).

Figure 9 - Comparison of computed values of maximum interface slip using "smeared" finite element model and discrete element model. Results in Figure 8 correspond to normalized load (normalized with respect to peak stress) of 0.48 (from Jung and Brown, 1991). 
Figure 10 - Conceptual representations of inter-particle interactions by means of bonds at contacts between spherical and irregularly shaped grains.

Figure 11 - Proposed single- and few-particle experiments to (i) evaluate conceptual models for interparticle interactions in discrete element code(s) and (ii) measure effect of cementation on bond constitutive properties. 


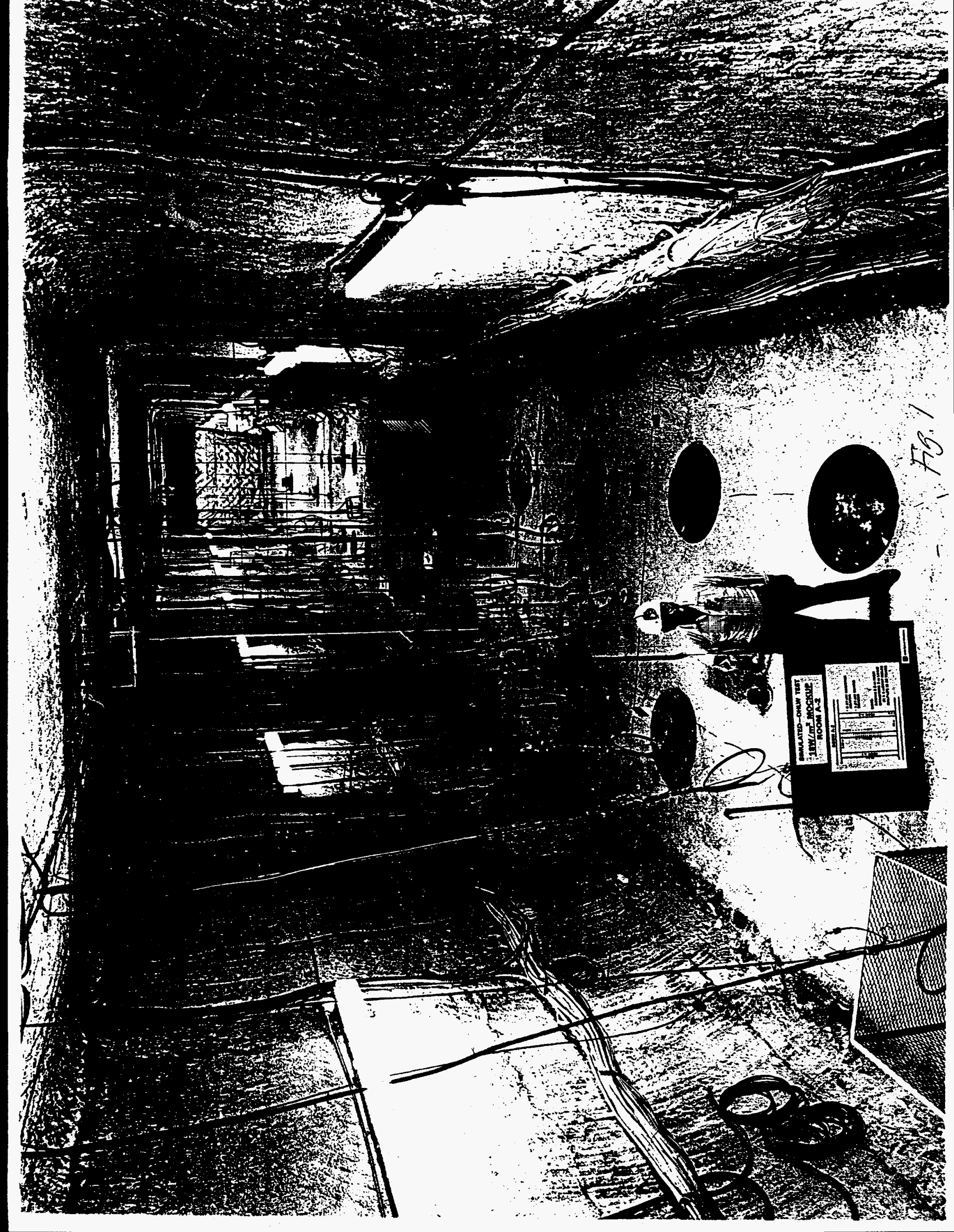



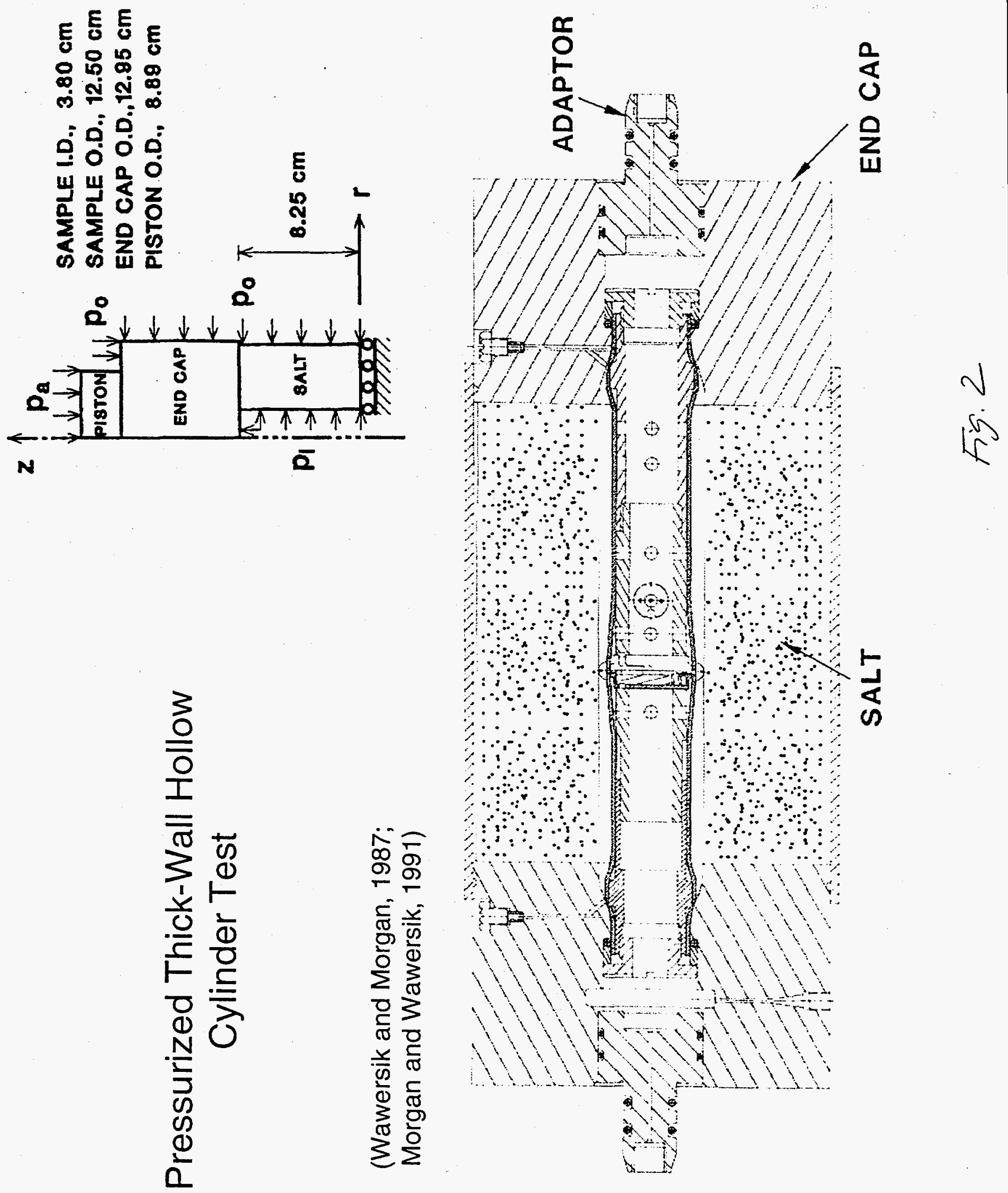


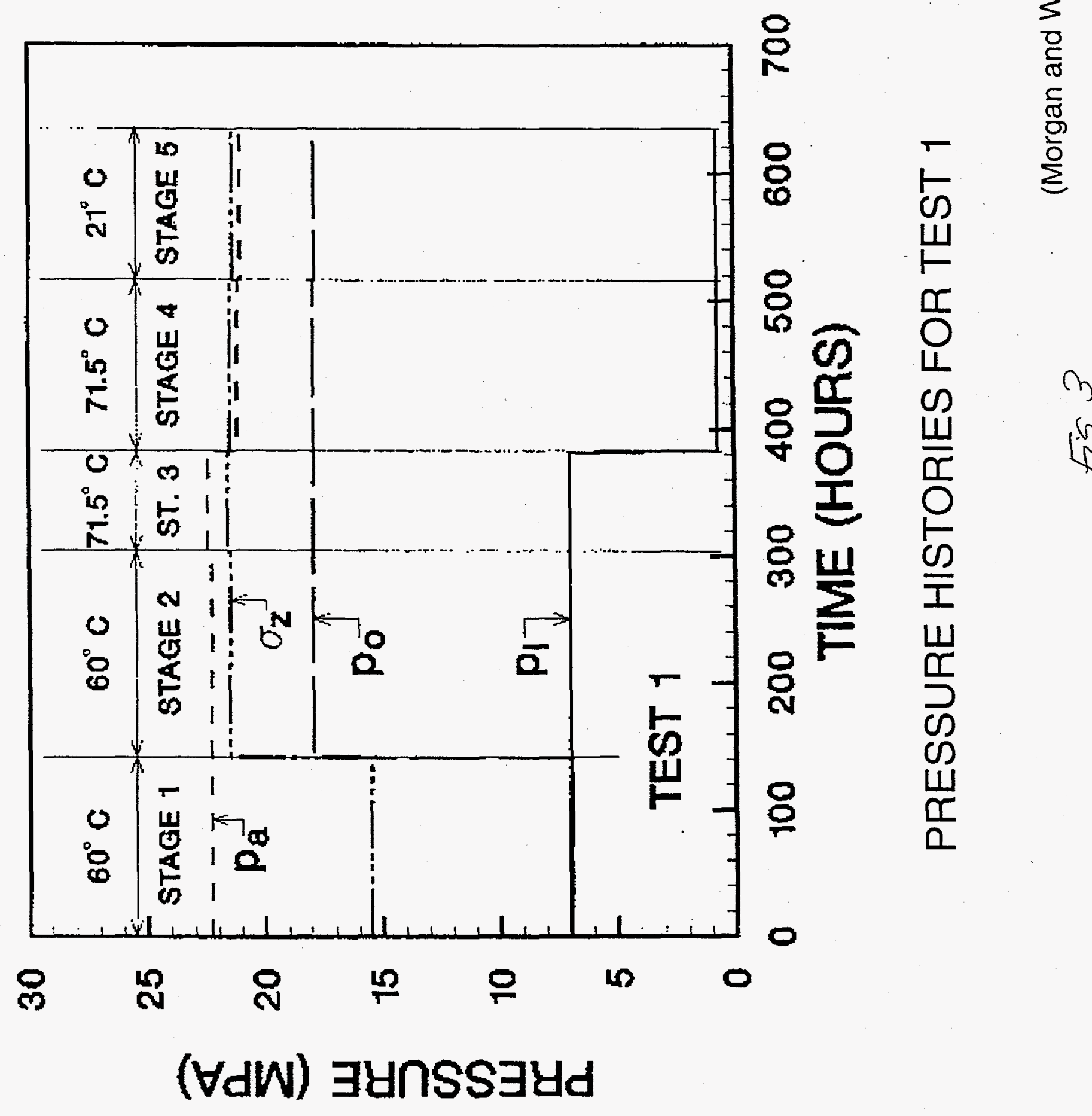




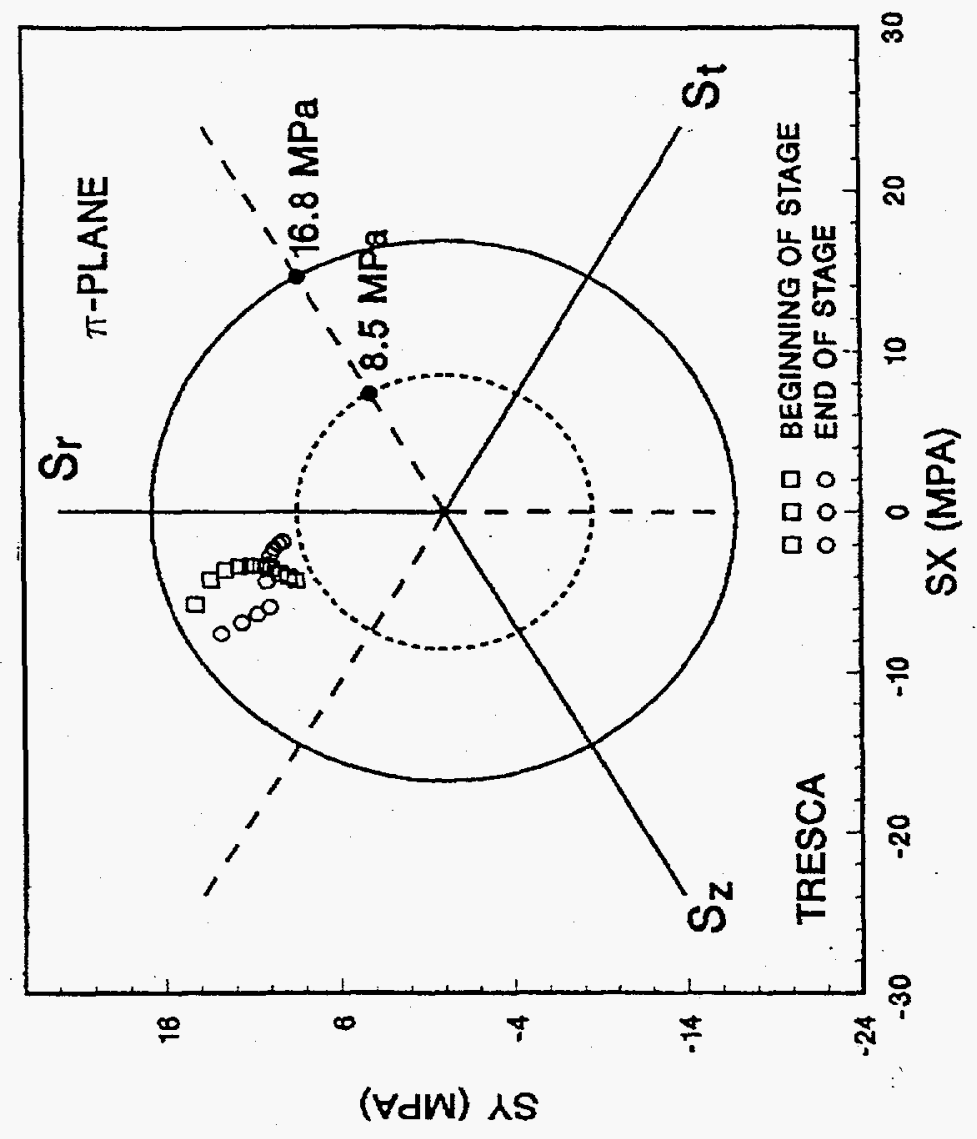

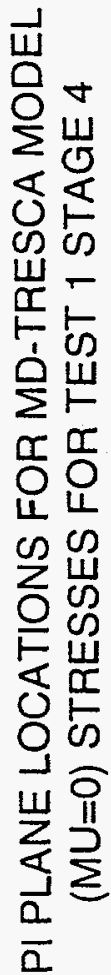

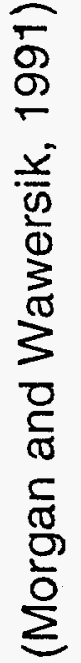

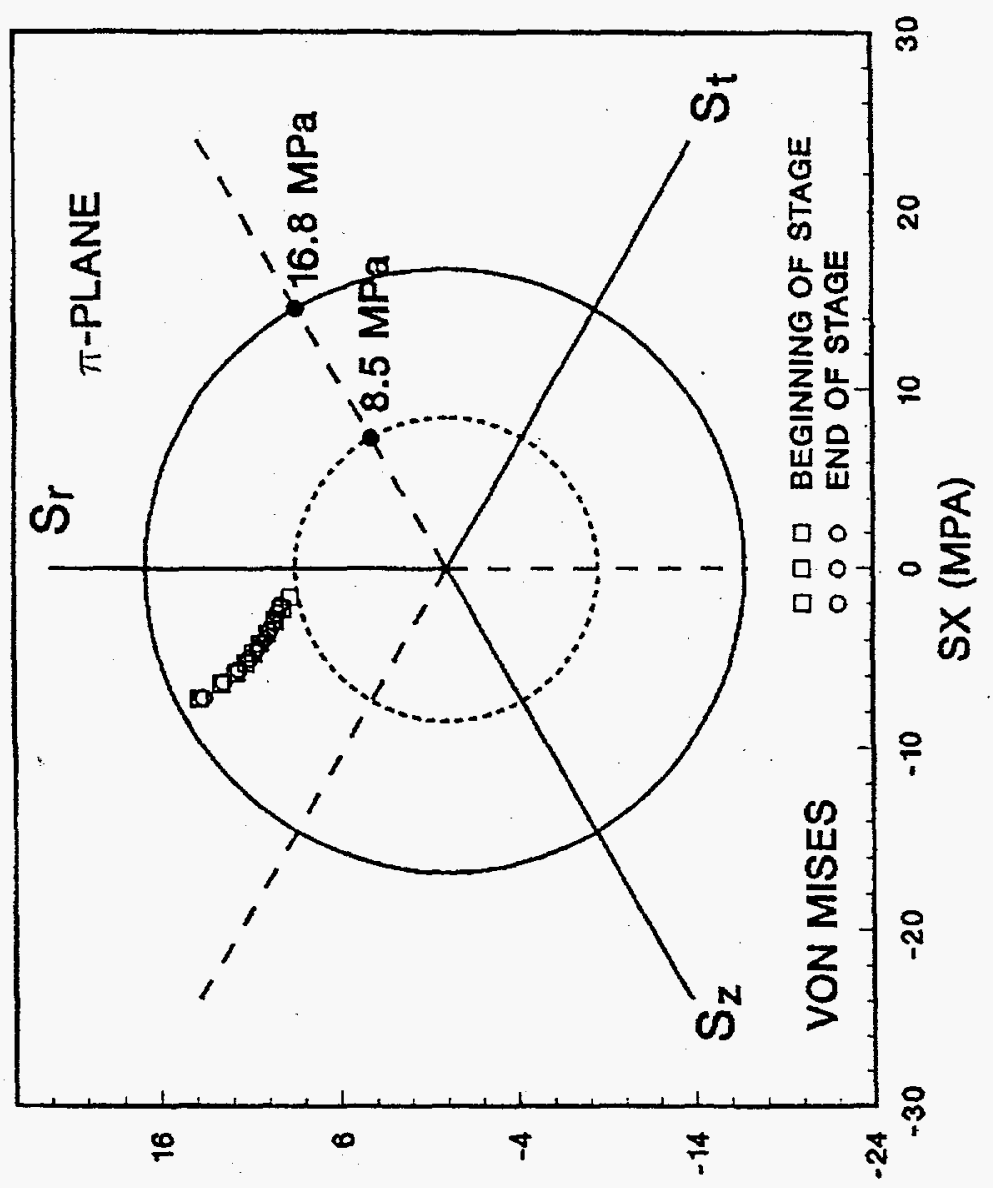

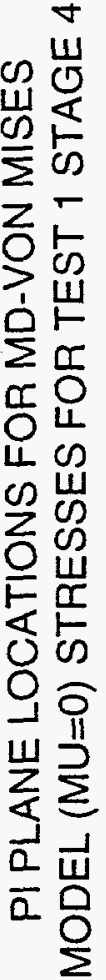

$(\forall d W) \wedge S$ 

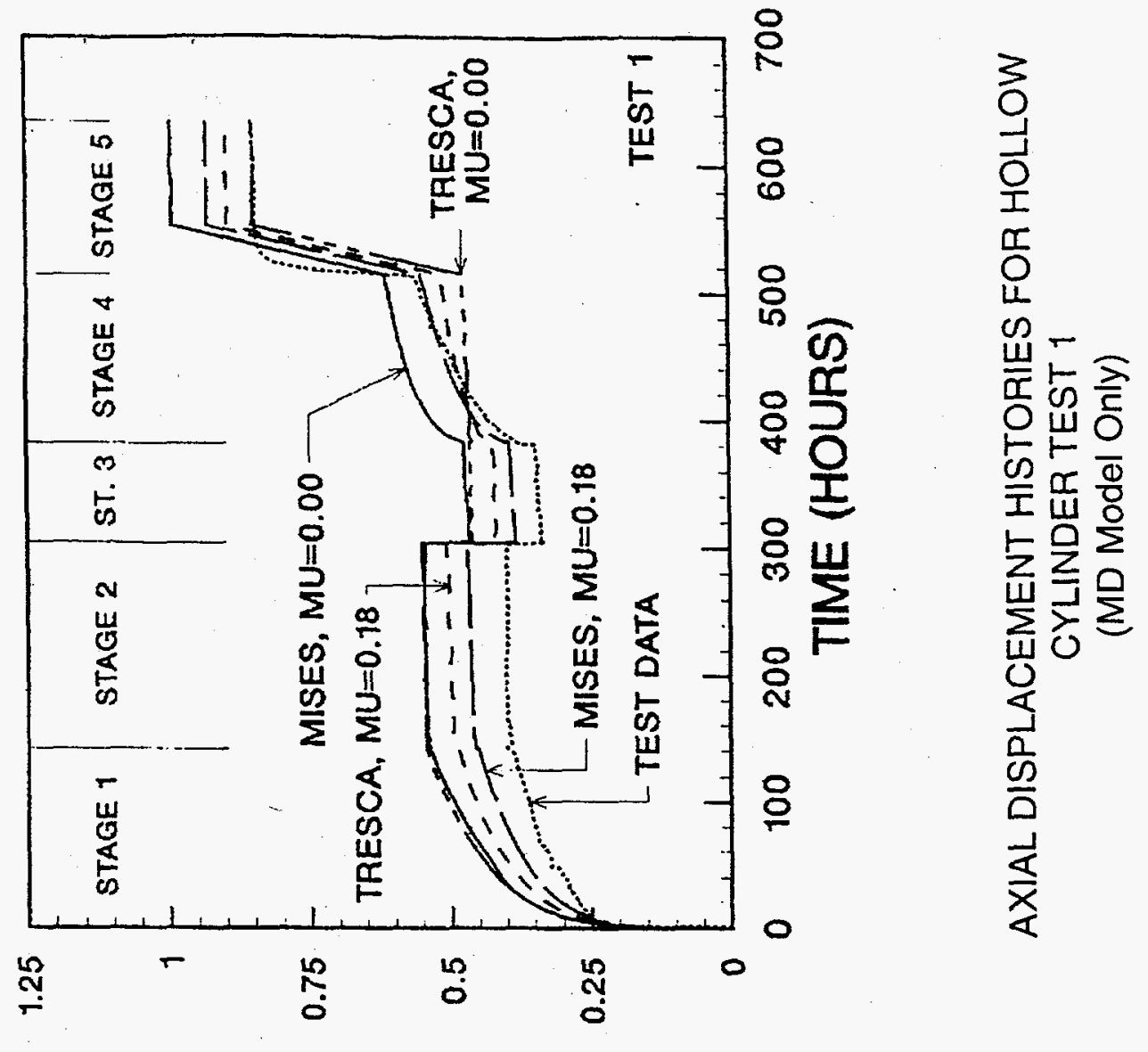

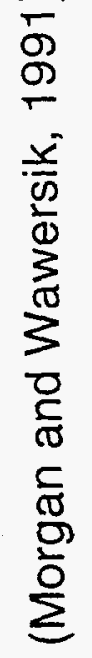

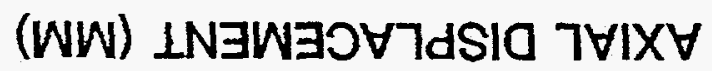

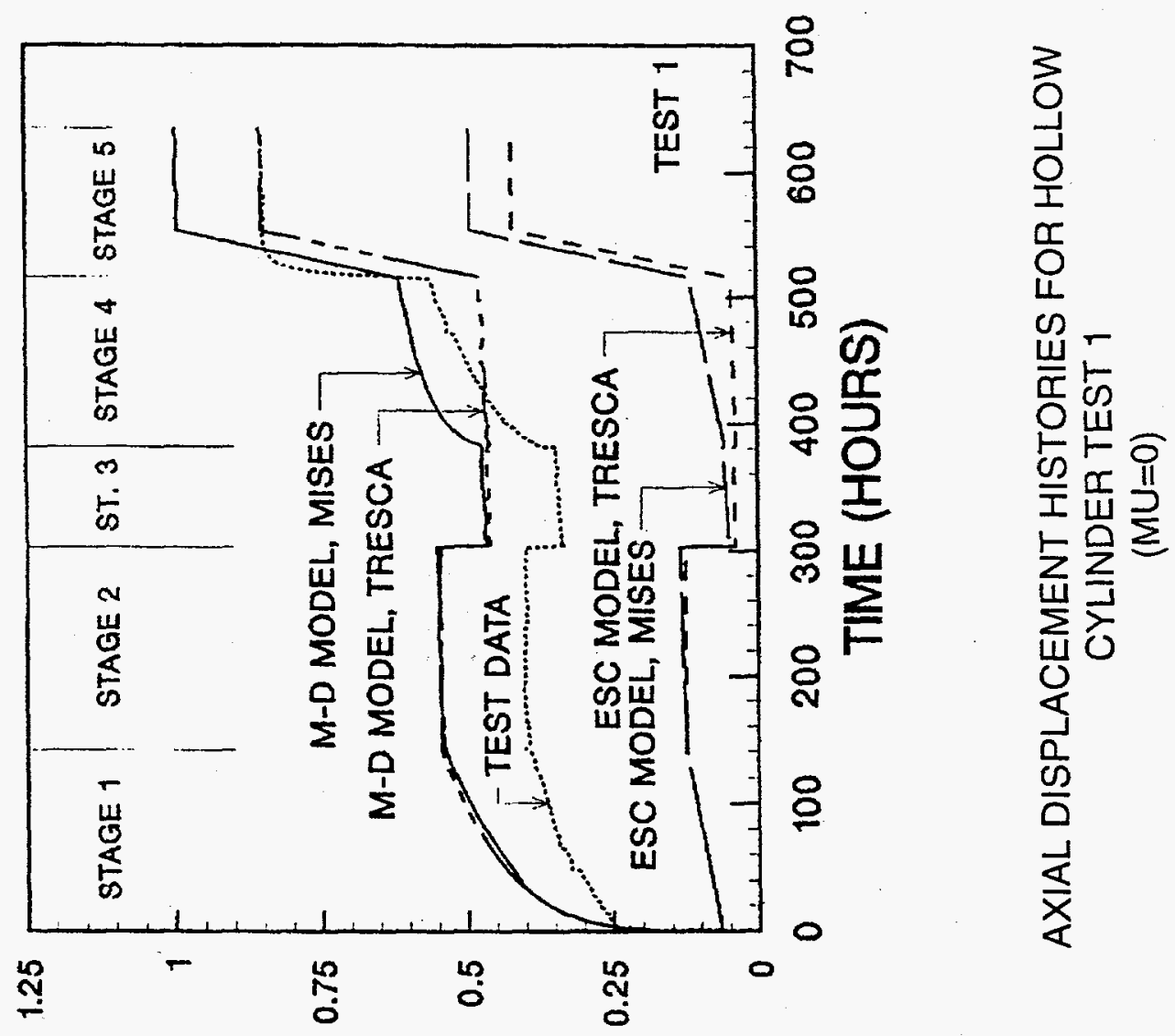

(WW) $\perp N \exists W \exists O \forall 7 d S I O ~ 7 \forall I X \forall$ 


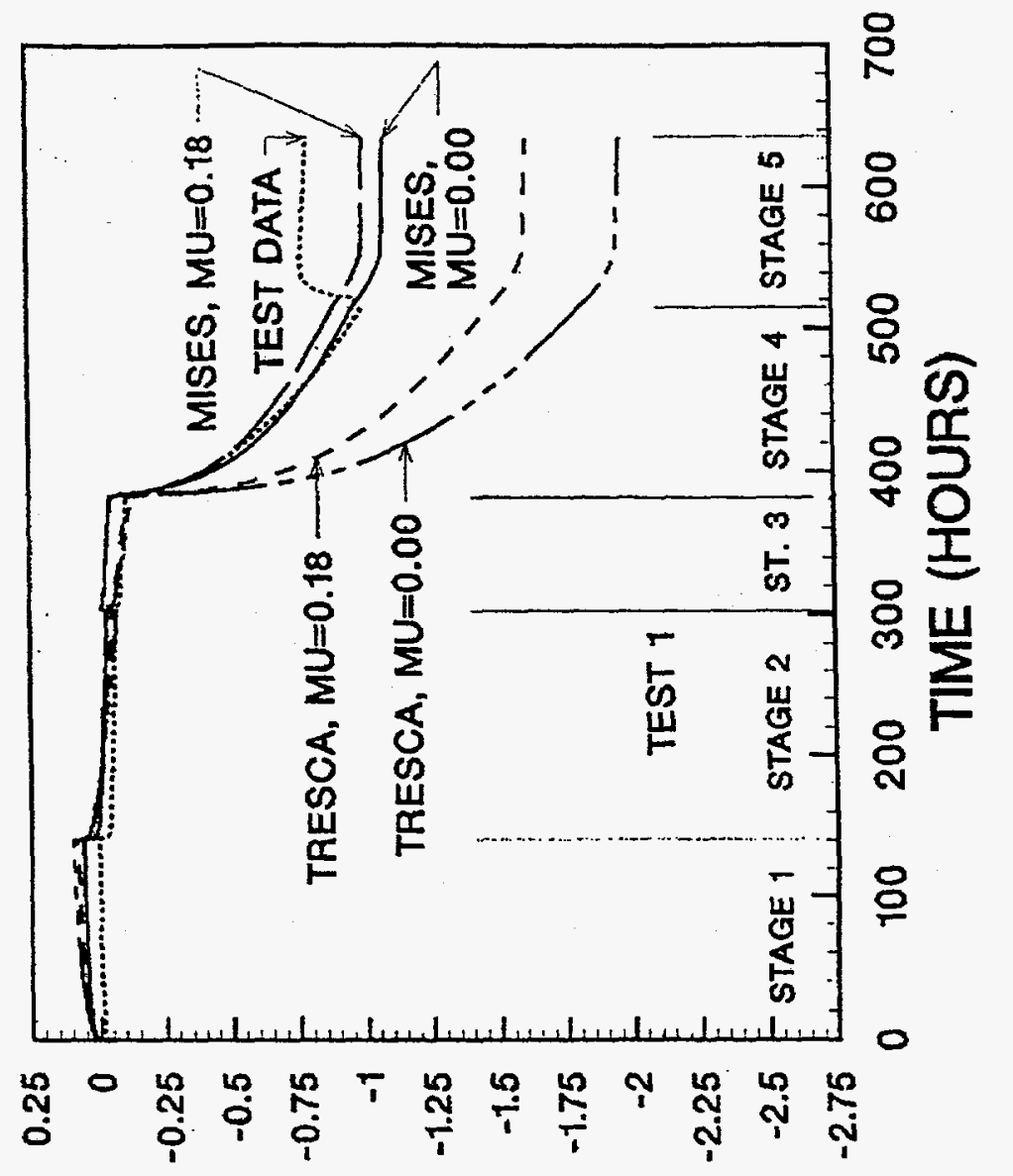

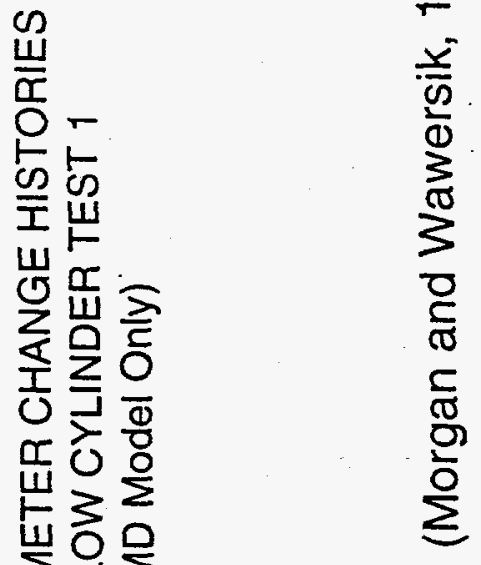

(WW) $\exists 9 N \forall H O$ y

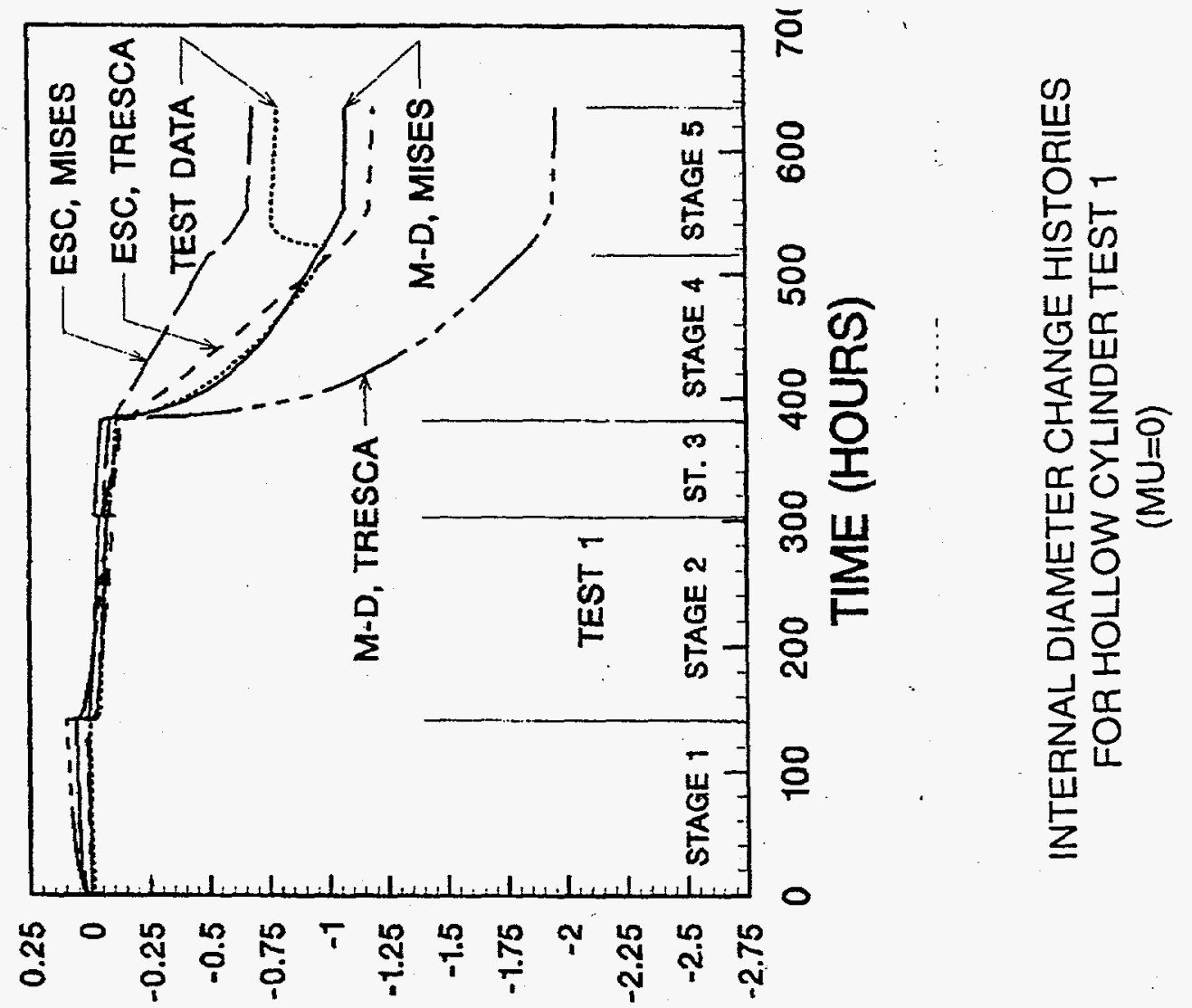

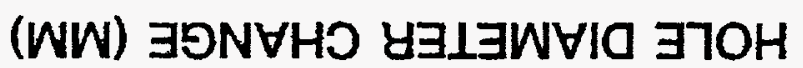




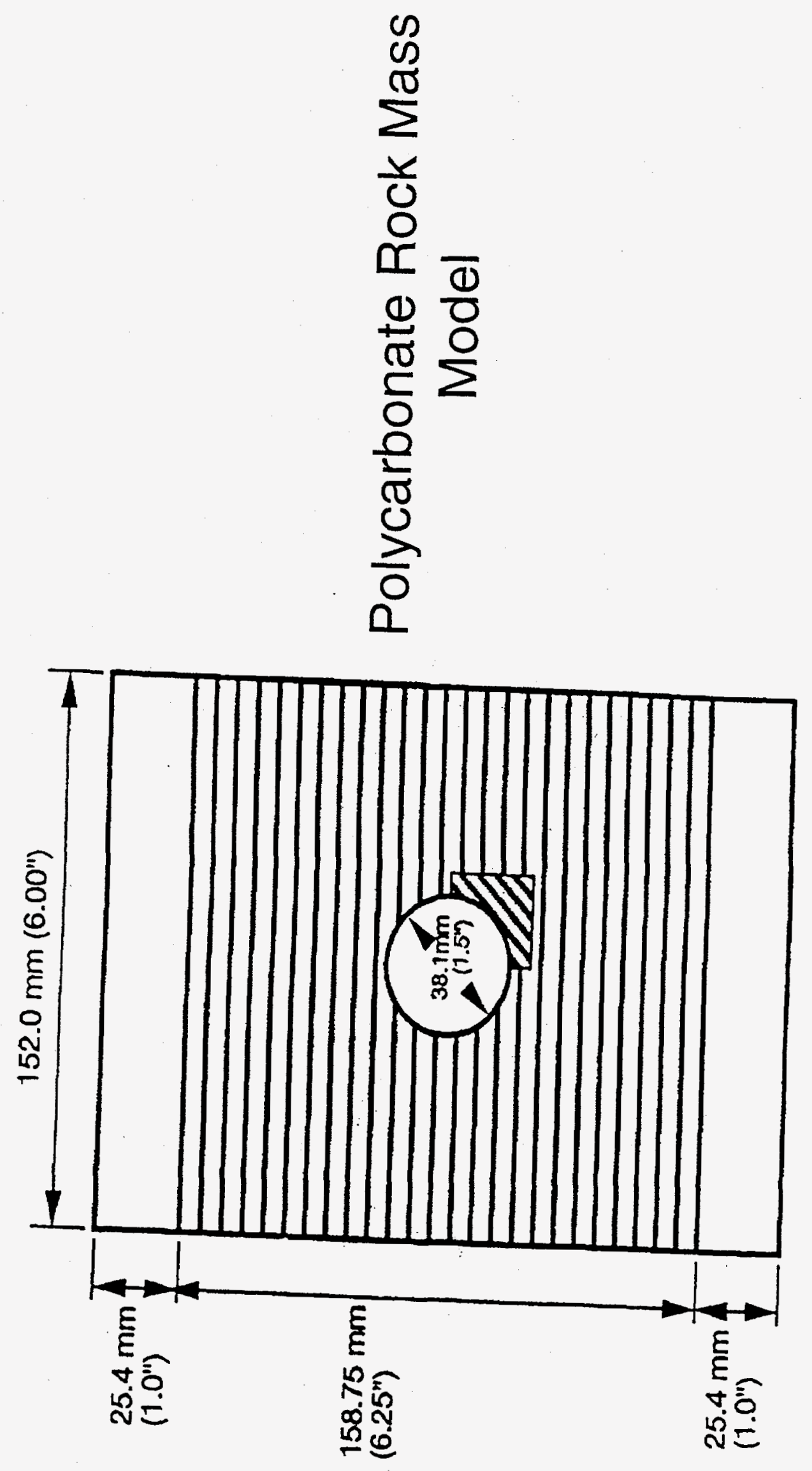

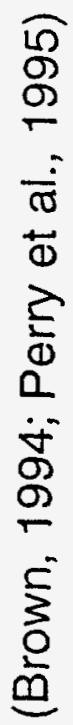




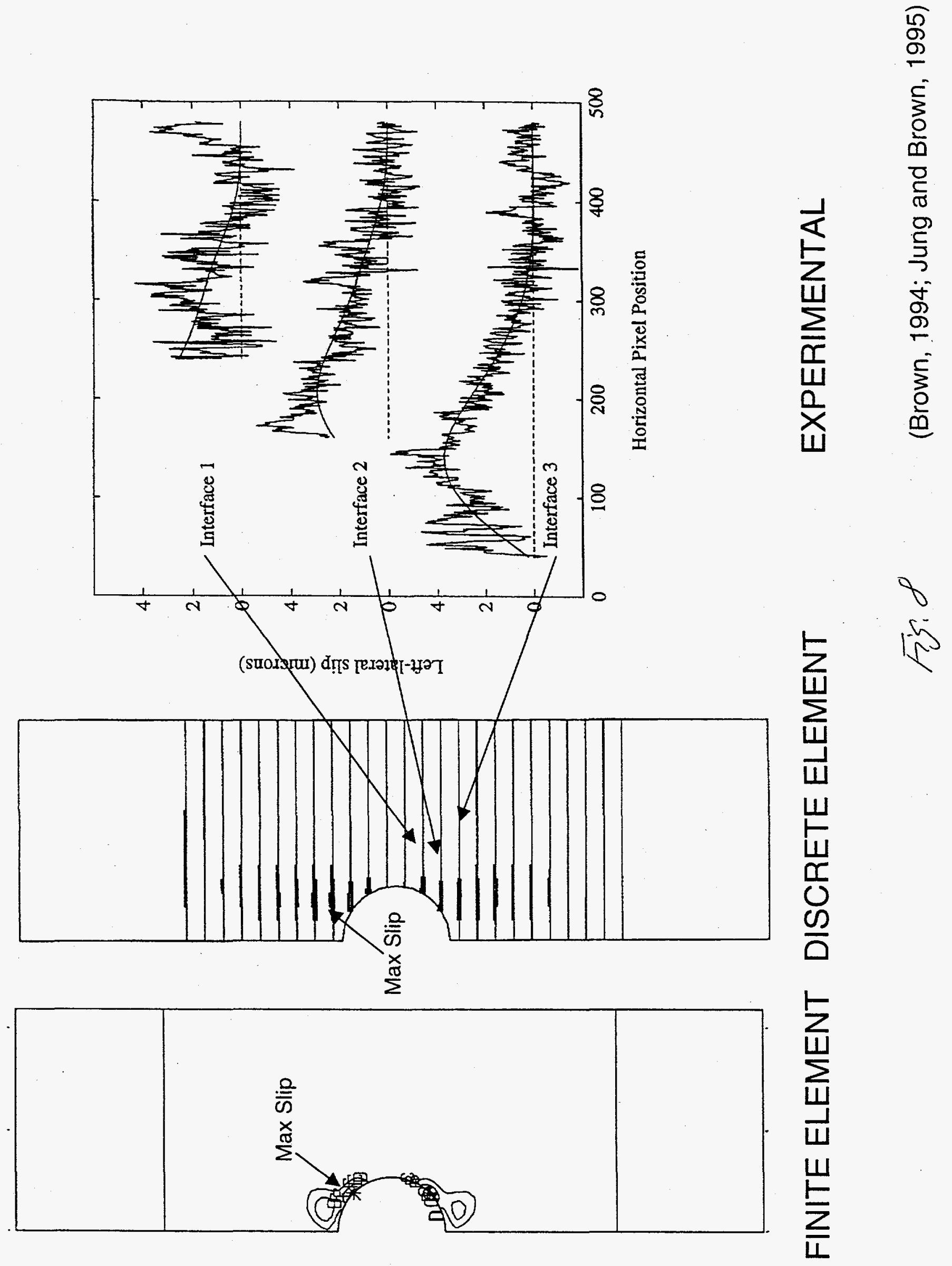




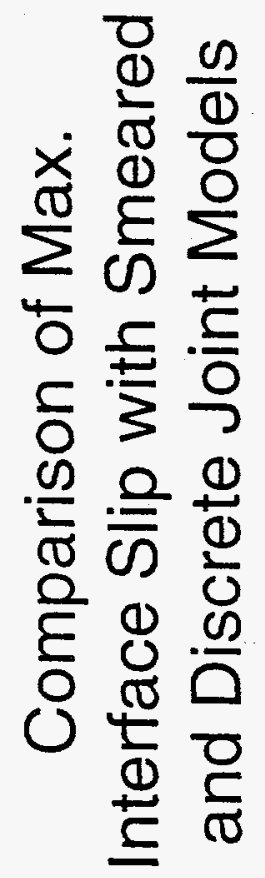

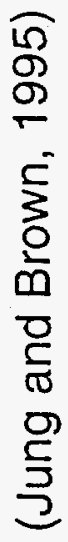

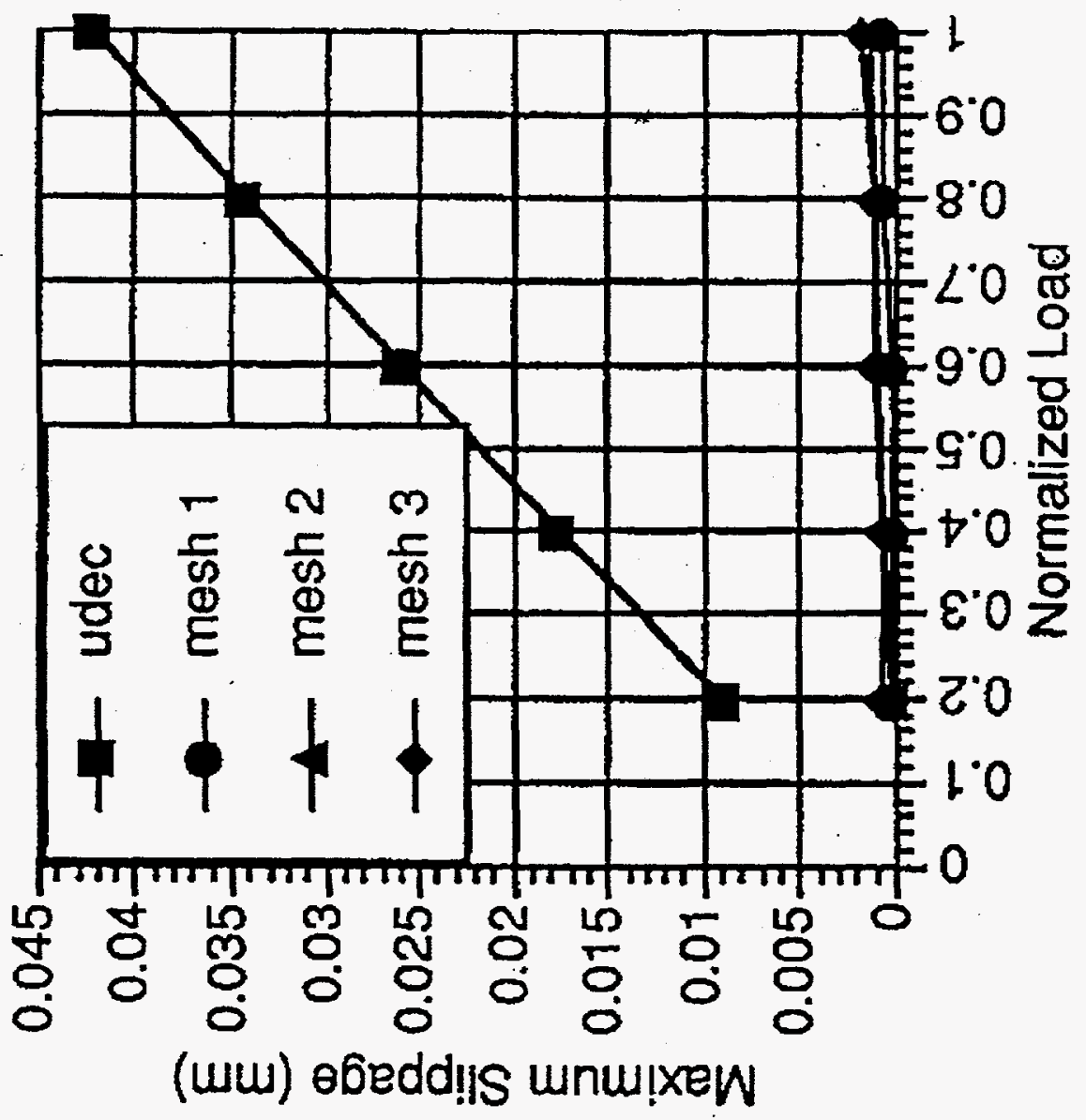



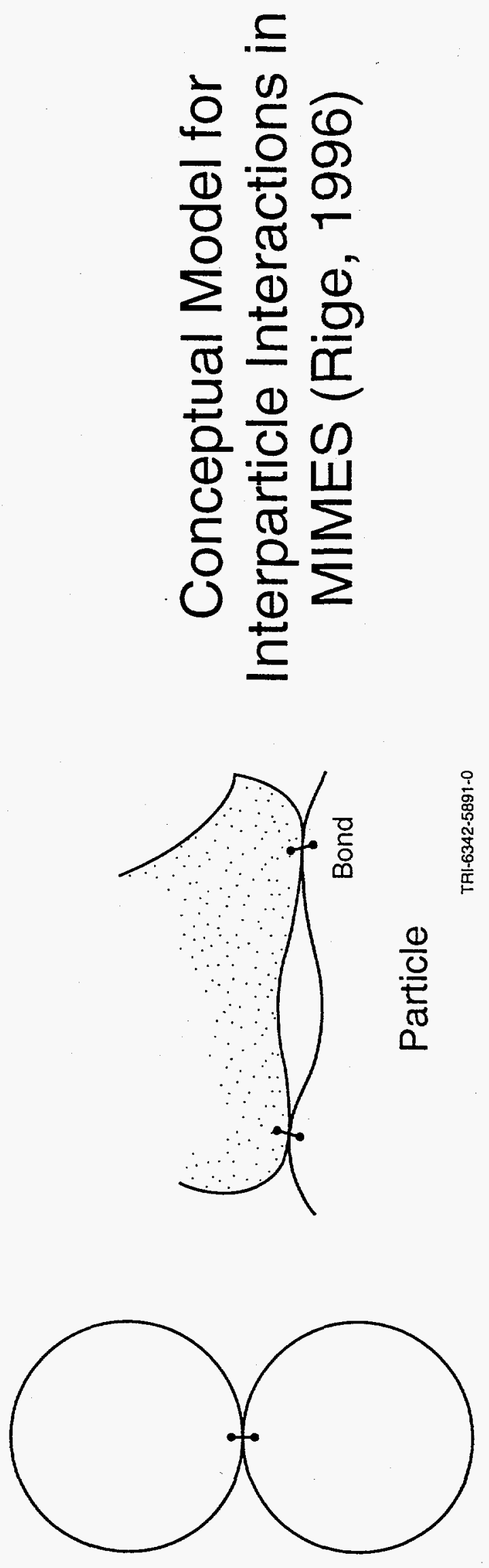

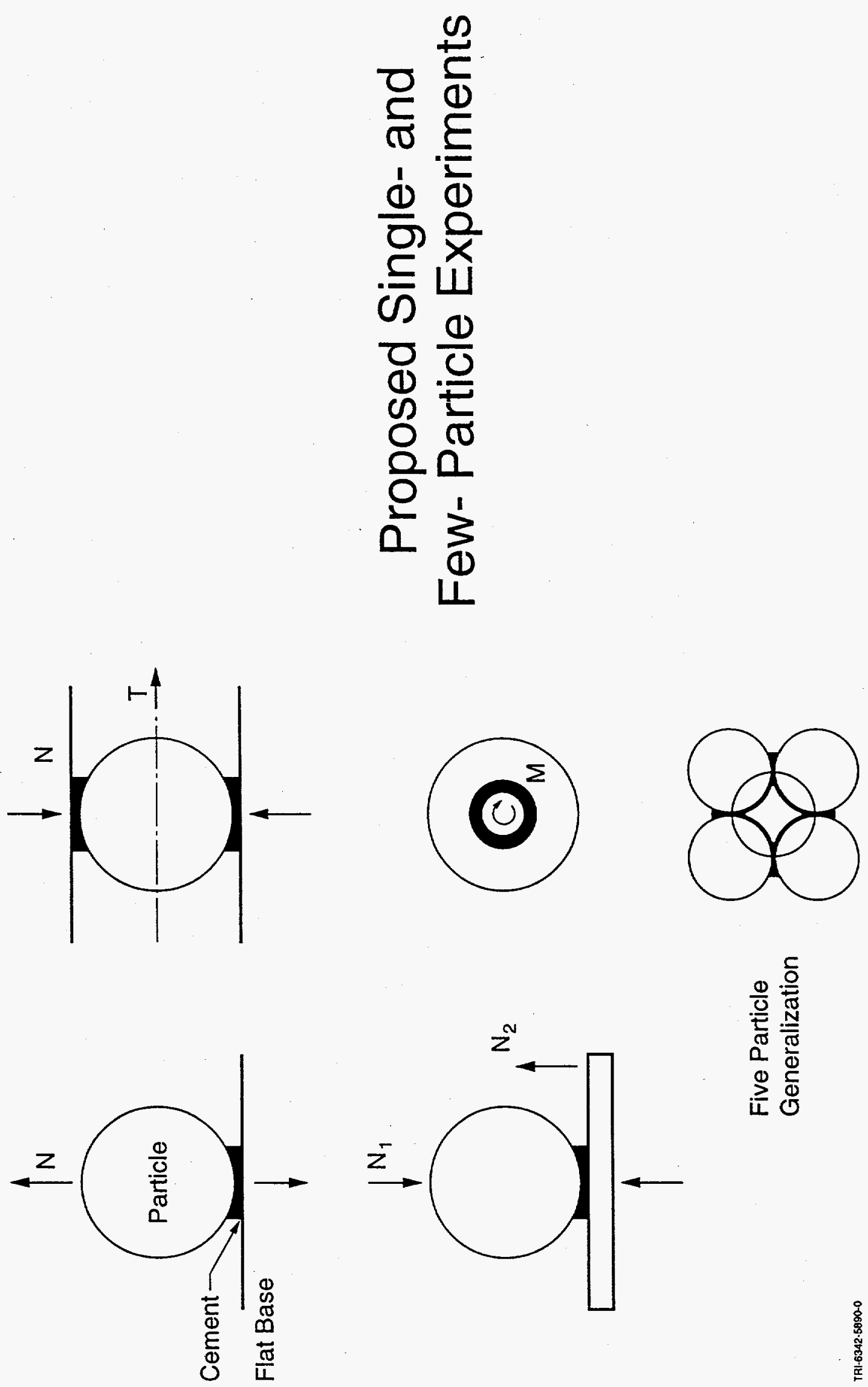

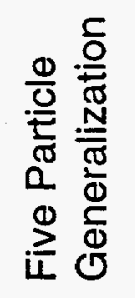

